\title{
Landsat-8 Satellite and Plan Position Indicator Lidar Observations for Retrieving Aerosol Optical Properties in the Lower Troposphere
}

\author{
Jamrud Aminuddin'1,2, Babag Purbantoro1,3, Nofel Lagrosas', Naohiro Manago', Hiroaki Kuze ${ }^{1}$ \\ ${ }^{1}$ Center for Environmental Remote Sensing, Chiba University, Chiba, Japan \\ ${ }^{2}$ Department of Physics, Faculty of Mathematics and Natural Science, Universitas Jenderal Soedirman, Purwokerto, Indonesia \\ ${ }^{3}$ Remote Sensing Technology and Data Center, Indonesian Institute of Aeronautics and Space (LAPAN), Jakarta, Indonesia \\ Email: jam rud.aminuddin@chiba-u.jp, jamrud.aminuddin@unsoed.ac.id
}

How to cite this paper: Aminuddin, J., Purbantoro, B., Lagrosas, N., Manago, N. and Kuze, H. (2018) Landsat-8 Satellite and Plan Position Indicator Lidar Observations for Retrieving Aerosol Optical Properties in the Lower Troposphere. Advances in Remote Sensing, 7, 183-202.

https://doi.org/10.4236/ars.2018.73013

Received: August 10, 2018

Accepted: September 8, 2018

Published: September 11, 2018

Copyright $(9) 2018$ by authors and Scientific Research Publishing Inc. This work is licensed under the Creative Commons Attribution International License (CC BY 4.0).

http://creativecommons.org/licenses/by/4.0/

\begin{abstract}
Observation of optical properties of atmospheric aerosols, especially their behavior near the surface level, is indispensable for better understanding of atmospheric environmental conditions. Concurrent observations of ground-based instruments and satellite-borne sensors are useful for attaining improved accuracy in the observation of relatively wide area. In the present paper, aerosol parameters in the lower troposphere are monitored using a plan position indicator (PPI) lidar, ground-sampling instruments (a nephelometer, an aethalometer, and optical particle counters), as well as a sunphotometer. The purpose of these observations is to retrieve the aerosol extinction coefficient (AEC) and aerosol optical thickness (AOT) simultaneously at the overpass time of Landsat-8 satellite. The PPI lidar, operated at $349 \mathrm{~nm}$, provides nearly horizontal distribution of AEC in the lower part of the atmospheric boundary layer. For solving the lidar equation, the boundary condition and lidar ratio are determined from the data of ground sampling instruments. The value of AOT, on the other hand, is derived from sunphotometer, and used to analyze the visible band imagery of Landsat- 8 satellite. The radiative transfer calculation is conducted using the MODTRAN code with the original aerosol type that has been determined from the ground sampling data coupled with the Mie scattering calculation. Reasonable agreement is found between the spatial distribution of AEC from the PPI lidar and that of AOT from the blue band (band 2) of Landsat-8. The influence of AOT on the values of apparent surface reflectance is also discussed.
\end{abstract}

\section{Keywords}

PPI Lidar, Mie Scattering, Fernald Analysis, Landsat-8, MODTRAN 


\section{Introduction}

Aerosol exerts impact on radiation balance of the Earth's atmosphere by modifying cloud characteristics in addition to scattering and absorption of solar radiation [1]. Besides, it affects biogeochemistry of earth materials by providing basis for heterogenic reactions [2]. In spite of these features, the current understanding level of aerosol behavior in the atmosphere is still insufficient for precise and reliable prediction of future climate [1] [3]. For describing aerosol radiative effect, we normally employ parameters such as aerosol optical thickness (AOT), Angstrom exponent, and aerosol extinction coefficient (AEC) [4] [5]. Various schemes have been proposed and tested to retrieve aerosol optical properties by means of ground-based remote sensing instruments [4].

Concurrent observations with ground-based instruments have been reported including MODerate resolution Imaging Spectroradiometer (MODIS) [6], Landsat-8 [7], and Himawari-8 [8] satellite imagery. Although the measurement of backscattering signals by means of lidar equipment can provide information on the spatial distribution information of AEC [9] [10] [11] [12], very few reports have been made for the lidar data analysis at the time of satellite overpass [4]. Therefore, in the present paper, a novel monitoring technique is proposed and demonstrated for retrieving nearly horizontal distribution of aerosol in the atmospheric boundary layer by combining the data from a plan-position indicator (PPI) lidar and visible images of Operational Land Imager (OLI) onboard Landsat- 8 satellite. Also, the data from ground-based, sampling instruments (an integrating nephelometer, an aethalometer, and particle counters) are effectively utilized to derive the boundary condition for solving the lidar equation [13] [14].

The atmospheric group of Center for Environmental Remote Sensing (CEReS), Chiba University, has developed and operated several lidar systems such as a multi-wavelength lidar system [14] [15] and portable automated lidar system [16]. The most updated system is called atmospheric data collection lidar system that incorporates a plan position indicator (PPI) and a slant-path (SP) lidar [4] [14] [15] [17]. Since the major target of these instruments is the aerosol particles in the atmospheric boundary layer, the elevation angles of these lidars are set to be small ( $4^{\circ}$ for PPI and $30^{\circ}$ for SP). Thus, instead of the far-end boundary conditions usually employed for vertical lidars, here we employ the near-end boundary conditions that are derived from the observations of ground-based sampling instruments. Also, the data from these instruments can provide the value of lidar ratio through the Mie scattering calculation [14] [17] [18] [19] [20].

The following section of this paper is outlined as follows. In Section 2, the method and formulation are explained. In Section 3, the results are presented and discussed, followed by Section 4 as the conclusion of this paper.

\section{Methodology}

The observations with ground-based instruments were carried out at Chiba University ( $35^{\circ} 37^{\prime} 30^{\prime \prime}$ and $\left.140^{\circ} 06^{\prime} 14^{\prime \prime}\right)$, located south-east of Tokyo metropolitan area (Figure 1). The results obtained on 1) October 27, 2016, 2) January 31 2017, 


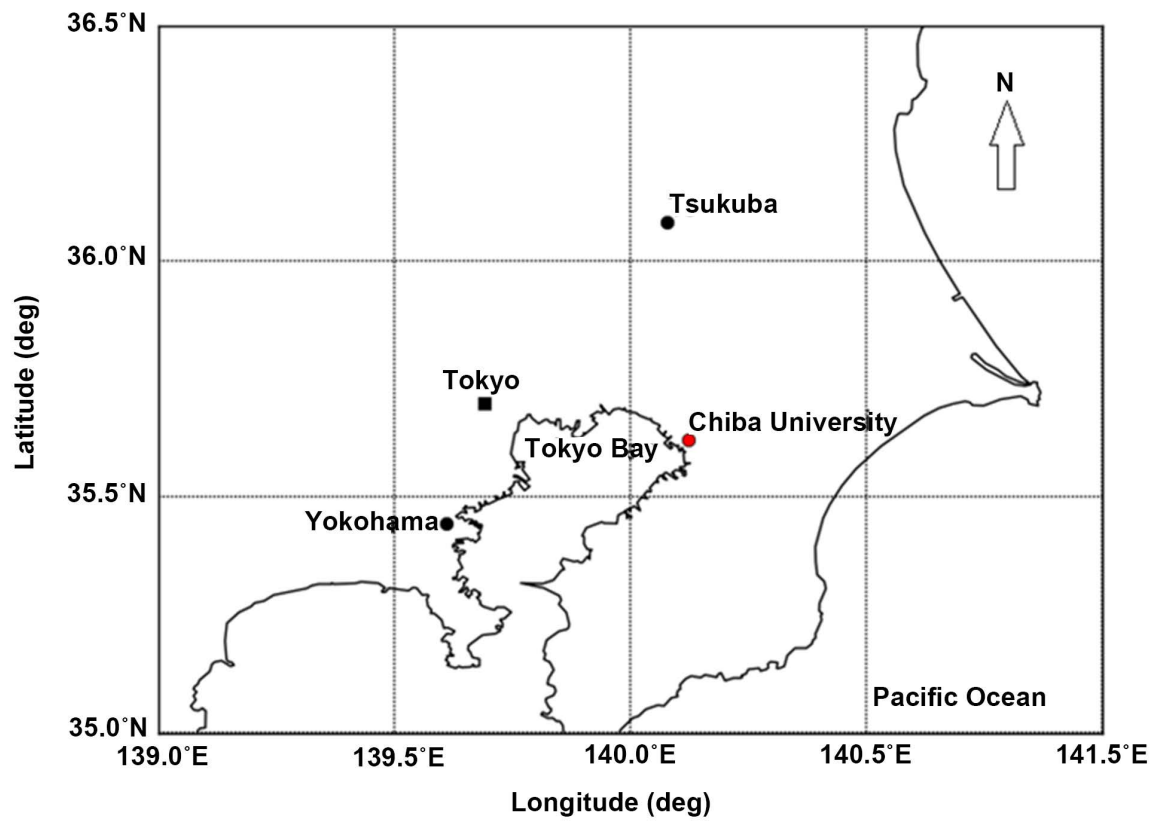

Figure 1. Location of Chiba University where the ground-based observations were made.

3) March 20 2017, and 4) May 232017 are reported in the present paper, representing the aerosol distributions over the Kanto plain area under nearly cloud-free conditions.

\subsection{Sampling Instrument and Mie Scattering Calculation}

The real-time data of aerosol particles in the atmospheric boundary layer are obtained using the following instruments routinely operated on the rooftop of the CEReS building ( $\sim 30$ and $\sim 50 \mathrm{~m}$ above ground and sea level, respectively): a three-wavelengths $(450,550$, and $700 \mathrm{~nm}$ ) integrating nephelometer (TSI, Model 3563), a seven-wavelengths (370, 470, 520, 590, 660, 880, and $950 \mathrm{~nm}$ ) aethalometer (Magee Scientific, AE-31), and optical particle counters (OPCs) that cover relatively small $(0.08,0.1,0.2,0.3$, and $0.5 \mu \mathrm{m})$ and relatively large $(0.3,0.5,1.0$, 2.0, and $5.0 \mu \mathrm{m}$ ) particle sizes (Rion, KC-22B, KC-01D and KC-01E). The aerosol extinction coefficient, $\alpha_{\text {exp }}$ can be calculated as a function of wavelength, $\lambda$, as the sum of scattering and absorption coefficients:

$$
\alpha_{\text {ext }}(\lambda)=\alpha_{s c a}(\lambda)+\alpha_{a b s}(\lambda),
$$

where $\alpha_{s c a}$ and $\alpha_{a b s}$ are the scattering and absorption coefficients derived from the nephelometer and aethalometer, respectively. The lidar ratio, $S_{1}$, is defined as the ratio between the extinction $\left(\alpha_{e x t}\right)$ and backscattering $(\beta)$ coefficients, and the following Mie scattering formulation can be used to calculate the value of $S_{1}$ :

$$
S_{1}=\frac{\alpha_{\text {ext }}}{\beta}=\frac{\int_{0}^{\infty} n^{(\text {model })}(r) \sigma_{e x t} \mathrm{~d}(\log r)}{\int_{0}^{\infty} n^{(\text {model })}(r)\left(\frac{\mathrm{d} \sigma_{s c a}}{\mathrm{~d} \Omega}\right)_{\theta=\pi} \mathrm{d}(\log r)},
$$


where $r$ is the particle radius,

$$
n^{\text {(model) }}(r)=\frac{\mathrm{d} N(r)}{\mathrm{d}(\log r)}=\sum_{i}^{k} \frac{N_{i}}{\sqrt{2 \pi} \log \sqrt{2 \pi} \log \sigma_{i}} \exp \left[-\frac{\left(\log r / r_{i}^{(m)}\right)^{2}}{2\left(\log \sigma_{i}\right)^{2}}\right]
$$

is the lognormal size distribution ( $k=1$ for mono-modal and $k=2$ for bimodal), and $\alpha_{e x t}$ and $\mathrm{d} s_{s c a} / \mathrm{d} \Omega$ are the extinction cross-section and differential cross-section, respectively [13] [17] [20]. The differential cross-section is related to the total scattering cross-section as

$$
\frac{\mathrm{d} \sigma_{s c a}}{\mathrm{~d} \Omega}=\sigma_{s c a} f(\cos \theta),
$$

where $f(\cos \theta)$ is the scattering phase function. The parameters that are used in the Mie calculation, namely, the mode concentration $\left(N_{i}\right)$, mode radius $\left(r_{i}^{(m)}\right)$, width $\left(\log \sigma_{i}\right)$, and both the real and imaginary parts of refractive index are determined so as to reproduce the data of ground-sampling instruments (scattering, absorption, and particle size) [14] [17] [18] [19] [20]. Also, the resulting aerosol parameters are used in the radiative transfer calculation for processing the Landsat-8 OLI data.

\subsection{PPI Lidar and Its Data Analysis}

The PPI lidar, installed at the same roof top of the CEReS building, is based on a diode-laser-pumped Nd:YLF laser operated at $349 \mathrm{~nm}$ with output energy of 60 $\mu \mathrm{J} /$ pulse and $300 \mathrm{~Hz}$ pulse repetition rate. A $30-\mathrm{cm}$ diameter Cassegrainian telescope coupled with a flat mirror tilted at $\sim 47^{\circ}$ is used to collect the backscattered signal, and a photo-multiplier tube (Hamamatsu, H10304-00) and a transient recorder (Licel, TR20-160) are employed for recording the signals. As shown in Figure 2, the whole system including the laser transmitter and telescope section can be rotated up to $360^{\circ}$ to cover all the horizontal directions. The maximum range of PPI observation is approximately $3 \mathrm{~km} \mathrm{[14]} \mathrm{[17]} \mathrm{[21].} \mathrm{The} \mathrm{signals} \mathrm{are}$ accumulated for $1 \mathrm{~min}$, and with the angular speed of $0.2 \mathrm{deg} / \mathrm{s}$, the 360-deg scan is completed in $30 \mathrm{~min}$ to retrieve the spatial distribution of AEC at $349 \mathrm{~nm}$.

The inversion analysis of PPI lidar signals is attained using the Fernald method [4] [15] [22] to obtain AEC on a nearly horizontal plane. The solution of the lidar equation is analytically described as

$$
\begin{aligned}
& \alpha_{1}(R)=-\frac{S_{1}(R)}{S_{2}} \alpha_{1}(R) \\
& +\frac{S_{1}(R) X(R) \exp \left\{2 \int_{R}^{R_{C}}\left[\frac{S_{1}\left(R^{\prime}\right) X\left(R^{\prime}\right)}{S_{2}}-1\right] \alpha_{1}\left(R^{\prime}\right) \mathrm{d} R^{\prime}\right\}}{\frac{X\left(R_{C}\right)}{\frac{\alpha_{1}\left(R_{C}\right)}{S_{1}(R)}+\frac{\alpha_{2}\left(R_{C}\right)}{S_{2}(R)}+\int_{R}^{R_{C}} S_{1}\left(R^{\prime}\right) X\left(R^{\prime}\right) 2 \int_{R}^{R_{C}}\left[\frac{S_{1}\left(R^{\prime}\right) X\left(R^{\prime}\right)}{S_{2}}-1\right] \alpha_{1}\left(R^{\prime}\right) \mathrm{d} R^{\prime}}}
\end{aligned}
$$




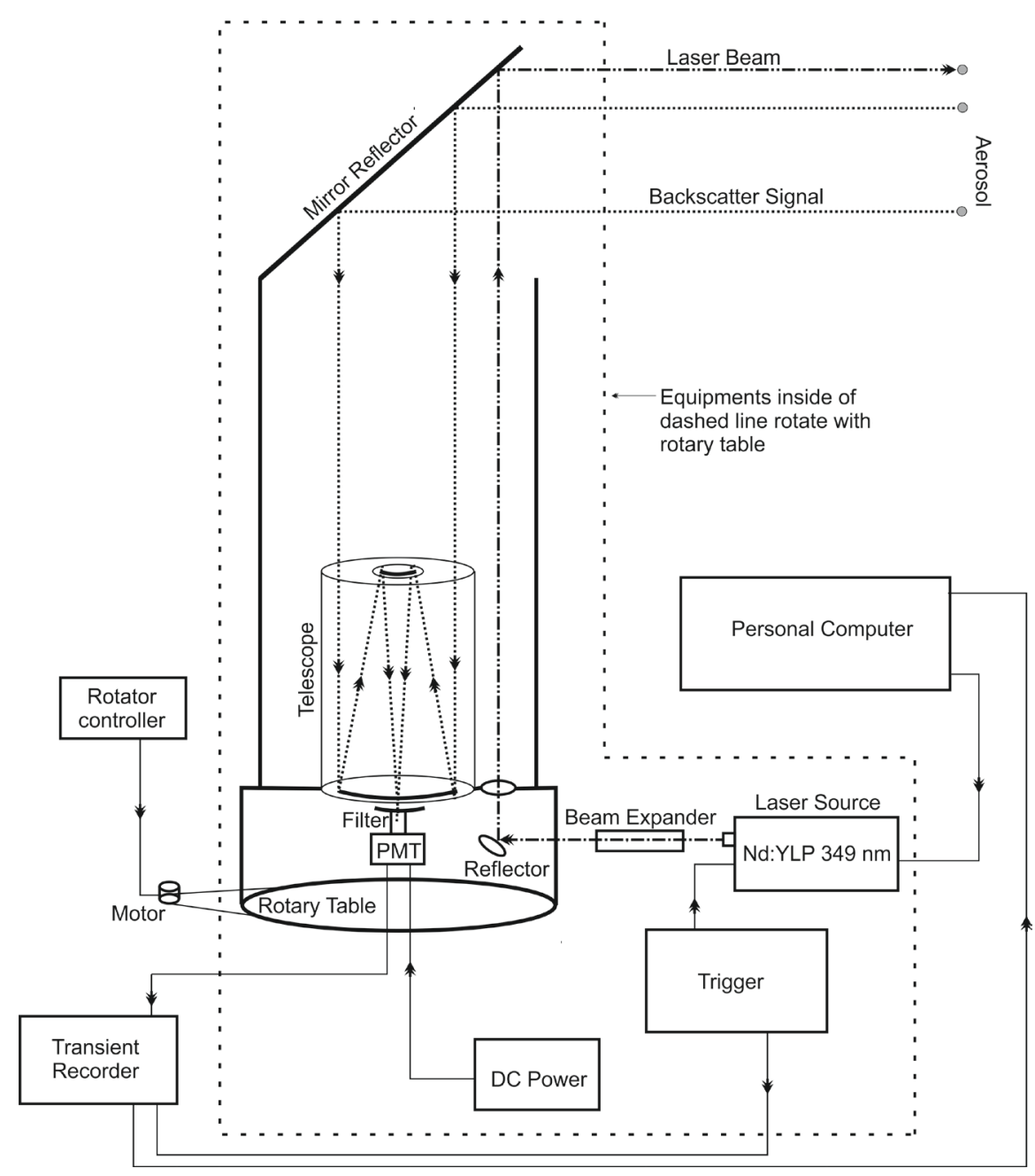

Figure 2. PPI lidar setup. The lidar system can measure the nearly horizontal spatial distribution of AEC in around $30 \mathrm{~min}$.

where $R$ is the range, $X(R)=R^{2} P(R)$ is the range-corrected signal, $R_{C}$ is the reference range, and the subscript 1 (2) refers to aerosol (air molecule) [22]. A single value of $S_{1}$ is assumed for analyzing PPI data. From the general property of Rayleigh scattering of air molecules, $S_{2}$ is assumed to be 8.52 sr [14] [17]. For vertical lidars, it is customary to assume a reference range at an altitude where aerosol distribution is negligibly small. Since this cannot be the case for the current analysis of the PPI lidar, we employ an iterative approach in which the values at $R_{C}$ are adjusted so that the resulting AEC at $R=0$ agrees with the value from sampling observations.

\subsection{AOT and Angstrom Exponent from Sunphotometer Measurement}

The values of AOT and Angstrom exponent are derived from the multi-band observation of a sunphotometer (Prede, PSF-100), routinely operated in CEReS. The measurement is made at the wavelengths of $368,500,678$, and $778 \mathrm{~nm}$. The 
Lambert-Beer law coupled with the Langley extrapolation method [5] [23] [24] is used to derive AOT:

$$
\tau_{A}(\lambda)=\frac{\ln I_{0}(\lambda)-\ln I(\lambda)}{m(\theta)}-\tau_{G}(\lambda)-\tau_{R}(\lambda) .
$$

Here the variables $\tau_{A}, \tau_{G}$, and $\tau_{R}$ represent the optical thickness due to aerosol, absorbing gas (ozone), and Rayleigh scattering, respectively; $I_{0}$ is the extra-terrestrial intensity of solar radiation (dependent on the seasonal change of the Sun-Earth distance), $I$ is the solar radiation intensity measured by the sunphotometer, and $m$ is the air mass dependent on the solar zenith angle, $\theta$. The value of $I_{0}$ can be determined by implementing the Langley extrapolation method on a clear-sky day with small aerosol loading [24].

Furthermore, the information on aerosol size distribution can be inferred from the wavelength dependence of AOT that can be expressed using Angstrom exponent [24] [25] [26] [27] [28]:

$$
p=-\ln \left[\frac{\tau_{A}\left(\lambda_{2}\right)}{\tau_{A}\left(\lambda_{1}\right)}\right] / \ln \left(\frac{\lambda_{2}}{\lambda_{1}}\right),
$$

which can easily be extended for multi-wavelength fitting. The value of $p$ is the order of unity. The value of Angstrom exponent becomes larger in the condition of the dominance of fine-mode aerosol, while it becomes smaller for the dominance of coarse-mode particles [29] [30] [31].

\subsection{Radiative Transfer Analysis of Landsat-8 Data}

Here the satellite measurement of aerosol distribution is studied using images of the OLI sensor onboard the Landsat- 8 satellite, since the data provide a fine resolution of $30 \mathrm{~m}$ [7]. The significant parameters related to satellite imagery are the pixel value in digital number $(\mathrm{DN})$, radiance $\left(\mathrm{Wm}^{-2} \cdot \mathrm{sr}^{-1} \cdot \mu \mathrm{m}^{-1}\right)$, and apparent reflectance (dimensionless). Every satellite has its own empirical equation(s) for converting the DN values to radiance $\left(L_{o b s}\right)$ and apparent reflectance $\left(\rho_{\text {ap }}\right)$ as a function of wavelength. For Landsat-8 OLI, the apparent reflectance is calculated using the procedure described elsewhere [7] [32] [33] [34] [35]:

$$
\begin{gathered}
\rho_{a p}(\lambda)=\frac{\pi d^{2}}{E(\lambda) \cos \theta_{s}} \times L_{o b s}(\lambda), \\
L_{o b s}(\lambda)=\frac{L_{M A X}-L_{M I N}}{Q_{C A L M A X}-Q_{C A L M I N}} \times\left(D N-Q_{C A L M I N}\right)+L_{M I N} .
\end{gathered}
$$

Here $\mathrm{Q}_{\text {CALMAX }}$ and $\mathrm{Q}_{\text {CALMIN }}$ are the maximum and minimum values of the quantized and calibrated pixel value in $\mathrm{DN} ; L_{M A X}$ and $L_{M I N}$ are the spectral radiance scaled to $Q_{C A L M A X}$ and $Q_{C A L M I N}$, respectively. Besides, parameters $d, E(\lambda)$, and $\theta_{s}$ stand for the Sun-Earth distance in astronomical unit (AU), solar irradiance at the top of atmosphere at $1 \mathrm{AU}$, and solar zenith angle, respectively.

The radiance components detected by a satellite sensor can be given schematically as shown in Figure 3. The value of ground reflectance is affected by spectral signatures of surface coverage such as vegetation, soil, water body, etc. 


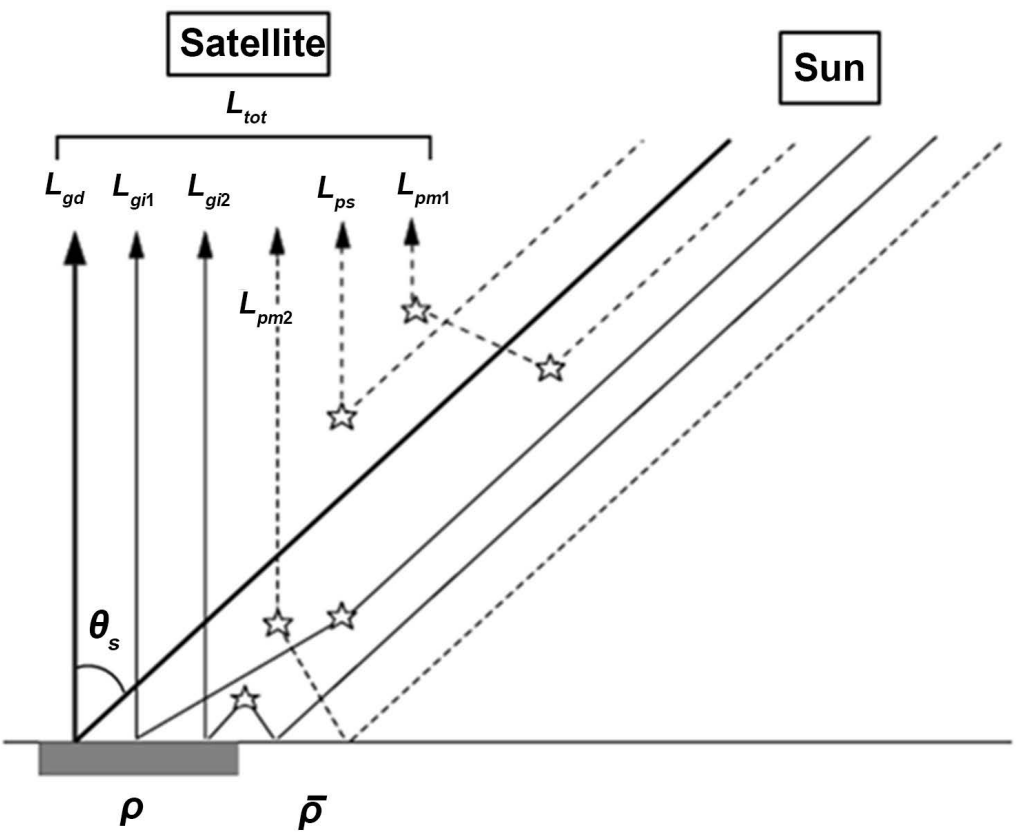

Figure 3. Radiance components in the radiative transfer formulation considering surface reflectance $(\rho)$, average reflectance $(\bar{\rho})$, and atmospheric scattering (star symbols). The parameter $\theta_{S}$ is the solar zenith angle. The following six components are illustrated in the figure: $L_{g d}$ (surface reflection of direct solar radiation), $L_{g i 1}$ (surface reflection of scattered solar radiation), $L_{g i 2}$ (surface reflection of sky radiance influenced by adjacency effect), $L_{p s}$ (path radiance due to single scattering), $L_{p m 1}$ (path radiance due to multiple scattering), and $L_{p m 2}$ (path radiance including adjacency effect).

Besides, scattering and absorption of air molecules and aerosol particles exert significant influence on the radiance value of each pixel. Therefore, radiative transfer calculation is indispensable for separating the atmospheric effects from the ground-reflected radiance in each satellite scene. In an early work, Chandrasekhar developed a radiative transfer equation where the scattering and absorption processes due to air molecule were considered [35] [36]. The atmospheric and observational parameters have been provided in radiative transfer codes such as LOWTRAN (LOW resolution atmospheric radiance and TRANsmittance) [37], MODTRAN (MODerate resolution atmospheric TRANsmission) [38] and 6S (Second Simulation of a Satellite Signal in the Solar Spectrum) [39] [40]. These codes have been applied in modeling radiative transfer processes to implement the atmospheric correction of various satellite data [41] [42] [43] [44] [45]. In the present work, we mainly use MODTRAN-5 [38] [42] [45] for the analysis of Landsat-8 OLI imagery.

Here we describe the basic features required for understanding the radiative transfer processes. As indicated in Figure 3, the total radiance at a sensor element, $L_{\text {tot }}(\lambda)$, can be separated into six different components as

$$
L_{t o t}(\lambda)=L_{g d}(\rho)+L_{g i_{1}}(\rho)+L_{g i_{2}}(\rho, \bar{\rho})+L_{p s}+L_{p m_{1}}+L_{p m_{2}}(\bar{\rho}) .
$$

Here, $L_{g d}$ and $L_{g i}=L_{g i 1}+L_{g i 2}$ are the radiance components reflected from the 
surface directly and indirectly, respectively: only the reflectance of the target pixel, $\rho=\rho(\lambda)$, is included in $L_{g i 1}$, while the reflectance averaged over adjacent pixels, $\bar{\rho}$, is also considered for $L_{g i 2}$. The last three terms on the right-hand side of Equation (9) represent path radiance components: $L_{p s}$ and $L_{p m 1}$ are the components arising from single and multiple scattering, respectively, whereas the adjacent surface reflection is also considered in $L_{p m 2}$. It is noted that on the right-hand side of Equation (9), the $\lambda$ dependence of each term has been omitted for the sake of simplicity. The radiance just after the surface scattering (which is assumed to be Lambertian) can be written as

$$
L_{g}(\lambda)=\frac{1}{\pi d^{2}} \rho(\lambda) E(\lambda) \cos \theta_{s} T\left(\lambda, \theta_{s}\right),
$$

where $T\left(\lambda, \theta_{s}\right)$ is the atmospheric transmittance of the incoming solar irradiance [40]. The resulting radiance at the sensor is given as

$$
L_{g d}(\lambda)=L_{g}(\lambda) T(\lambda, 0),
$$

where $T(\lambda, 0)$ is the transmittance when the satellite observation is made toward the nadir direction, as is the case of Landsat-8 OLI. Detailed formulation and modification of the radiative transfer equation including the target reflectance $(\rho)$, average reflectance $(\bar{\rho})$, transmittance $(T)$, and some other parameters can be found in a satellite guide and references therein [46].

The determination of AOT from each pixel of a satellite image can be carried out as follows. In order to implement the radiative transfer simulation on a satellite pixel, the aerosol model has to be specified with the value of AOT, usually in the form of $\tau_{A}(550)=\tau_{550}$, the AOT at $550 \mathrm{~nm}$. Once the pixel reflectance $(\rho)$ is known, the value of $L_{t o t}(\lambda)$ can be calculated with the simulation. Then, the value of $\tau_{550}$ can be uniquely determined from the condition that $L_{t o t}(\lambda)$ is equal to the observed radiance, $L_{o b s}(\lambda)$, given in Equation (8). Practically, the implementation of this procedure is facilitated by constructing a lookup table, which summarizes the behavior of $\rho_{a p}$ as a function of $\rho$ and $\tau_{550}$. Also, it can be pointed out that by combining Equations (8)-(11), one obtains the following relation between the apparent reflectance and reflectance:

$$
\begin{aligned}
\rho_{a p}(\lambda) & =\frac{\pi d^{2}}{E(\lambda) \cos \theta_{s}} L_{o b s}(\lambda)=\frac{\pi d^{2}}{E(\lambda) \cos \theta_{s}} L_{t o t}(\lambda) \\
& =\rho(\lambda) T\left(\lambda, \theta_{s}\right) T(\lambda, 0)+\frac{\pi d^{2}}{E(\lambda) \cos \theta_{s}}\left(L_{g}+L_{p}\right)
\end{aligned}
$$

Here $L_{g}$ and $L_{p}$ stand for the ground reflectance (other than $L_{g d}$ ) and atmospheric scattering terms in Equation (9), respectively. When aerosol loading is limited and wavelength is not too short, both of $L_{g}$ and $L_{p}$ become small, representing some remaining contribution from the molecular (Rayleigh) scattering. Therefore, to a good approximation, we obtain

$$
\rho_{a p}(\lambda) \cong \rho(\lambda) \exp \left[-(1+m) \tau_{A}(\lambda)\right],
$$

where $m=\left(\cos \theta_{s}\right)^{-1}$ is the air mass. This equation is useful for estimating the 
value of AOT. Among the nine bands of Landsat-8, band 2 centered at $482 \mathrm{~nm}$ is used for the present analysis. The radiance that represents band- $i$ can be calculated as

$$
L_{i}=\int_{\lambda_{1}}^{\lambda_{2}} g_{i}(\lambda) L_{t o t}(\lambda) \mathrm{d} \lambda / \int_{\lambda_{1}}^{\lambda_{2}} g_{i}(\lambda) \mathrm{d} \lambda,
$$

where $g_{i}(\lambda)$ is the band response function covering the wavelength range from $\lambda_{1}$ to $\lambda_{2}$.

\section{Results and Discussion}

\subsection{Aerosol Characterization Using Ground-Based Instruments}

The values of AEC, Angstrom exponent as well as lidar ratio are determined using the data of ground-based instruments at the time of Landsat- 8 overpass. Figure 4 shows an example of the results of Mie scattering calculation. The size distribution is fixed to the observed values of OPC, leading to the determination of the parameters (mono-modal in this case) of $r_{i}$ and $\sigma_{i}$ in Equation (3). The real and imaginary parts of the complex refractive index (which are assumed to be independent of wavelength) are determined so as to reproduce the observed wavelength dependence of the scattering and absorption coefficients measured with the nephelometer and aethalometer. It is noted that before this analysis, the scattering data from the integrating nephelometer are subjected to the truncation error correction, which is related to the loss of contributions from relatively coarse particles, as well as the correction due to the evaporation of hygroscopic aerosols when the particles are introduced into the scattering volume of the instrument from ambient conditions with relative humidity higher than around $50 \%$ [47]. The value of Angstrom exponent is calculated from the AOT values, $\tau_{A}(\lambda)$, which in turn have been retrieved from the sunphotometer observation using Equation (6).

The value of lidar ratio, $S_{1}$, can readily be obtained from the phase function information provided from the Mie scattering calculation. In the case of Figure 4 , the value of $S_{1}=62.5 \mathrm{sr}$ obtained for $\lambda=349 \mathrm{~nm}$ is employed for implementing the Fernald analysis given by Equation (5). The resulting parameters, namely, the size distribution parameters and refractive index characterize aerosol in the atmospheric boundary layer, are utilized also as input parameters in the radiative transfer calculation using MODTRAN.

Table 1 shows the resulting values of lidar ratio (for $349 \mathrm{~nm}$ ) with the values of AEC and Angstrom exponent. Here we have chosen the wavelength of 482 $\mathrm{nm}$ (the center wavelength of band 2 of Landsat-8 OLI) to indicate AEC, though the conversion to other wavelength can easily be made with the help of Angstrom exponent using Equation (7). The AEC data in Table 1 indicate that aerosol loading was small on 27 October 27 and 31 January 2017, while a turbid condition occurred on 20 March 2017. The situation on 23 May 2017 was an intermediate case, though the relative humidity was rather high $(58 \%)$ on that day. 


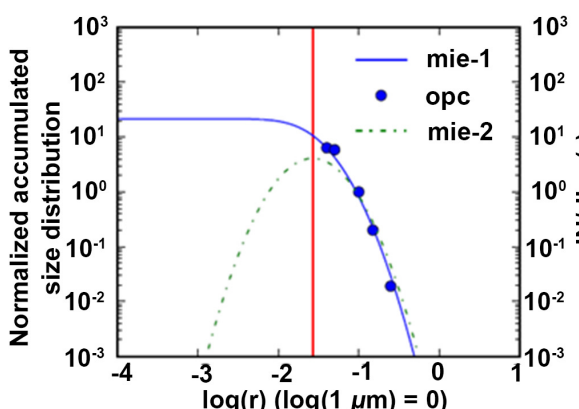

(a)

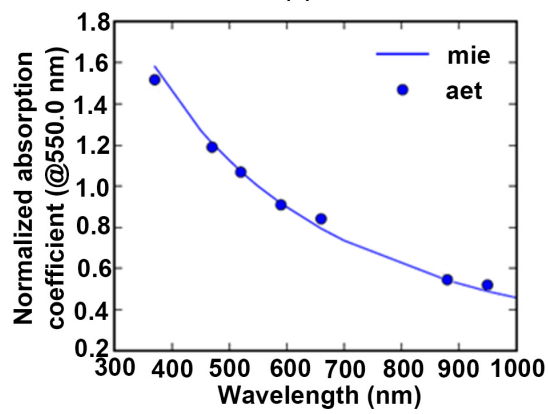

(c)

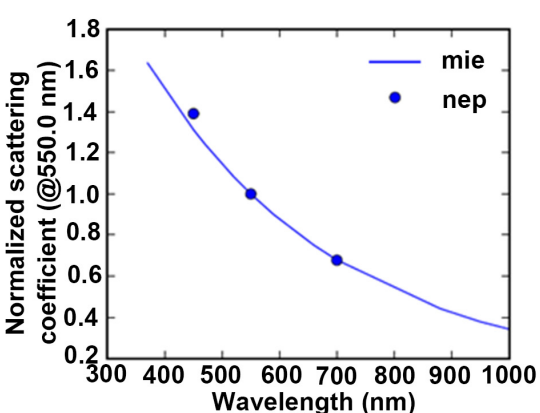

(b)

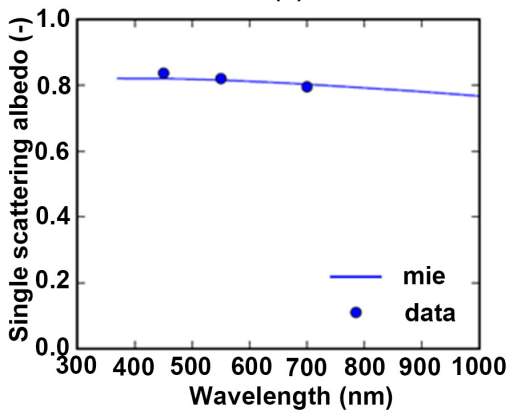

(d)

Figure 4. Fitting of observed parameters with Mie scattering calculation for the case of data observed at 10:00 (Japan Standard Time, JST) on January 31, 2017: (a) Size distribution data from the OPC (mie-1 is the fitting using a modified aerosol model and mie- 2 is the mono-modal lognormal function); (b) Scattering coefficient from the nephelometer; (c) Absorption coefficient from the aethalometer; and (d) Single scattering albedo given as the ratio between the scattering and extinction coefficients. In each of (b)-(d), the best-fit result of Mie calculation is shown with a solid line. The resulting parameters are summarized in Table 1 and Table 2.

Table 1. Lidar ratio at the PPI lidar wavelength $(349 \mathrm{~nm})$, the value of AEC $\left(\alpha_{\text {ext }}\right)$ in the boundary layer at the wavelength of Landsat-8 band-2 (482 nm), Angstrom exponent $(p)$, relative humidity $(\mathrm{RH})$, and temperature $(T)$.

\begin{tabular}{cccccc}
\hline Date & $\mathcal{S}_{1}(\mathrm{sr})$ & $\alpha_{\text {ext }}\left(\mathrm{km}^{-1}\right)$ & $p$ & $\mathrm{RH}(\%)$ & $T\left({ }^{\circ} \mathrm{C}\right)$ \\
\hline 27 October 2016 & 74.10 & 0.075 & 1.422 & 45 & 24 \\
31 January 2017 & 62.50 & 0.056 & 1.250 & 30 & 7 \\
20 March 2017 & 48.90 & 0.330 & 1.750 & 26 & 15 \\
23 May 2017 & 61.70 & 0.120 & 1.578 & 58 & 25 \\
\hline
\end{tabular}

\subsection{Analysis of Landsat-8 Data}

Table 2 lists the parameters employed in the MODTRAN calculation to simulate the total radiance observed by Landsat- 8 . The day of year (DOY) indicates the Julian day of Landsat- 8 satellite overpass. The satellite zenith and azimuth angles of $-0.001^{\circ}$ and $181.29^{\circ}$, respectively, are taken from the metadata of satellites together with the solar zenith angle (SZA) and solar azimuth angle (SAA). The atmospheric models are selected based on the season in mid-latitude. The parameters describing aerosol type consist of $N$ (density), $r$ (mode radius), $\log \sigma$ 
Table 2. Important parameters and conditions used as MODTRAN input for calculating radiance for the Landsat- 8 images over the Kanto area. AOT refers to the value at $482 \mathrm{~nm}$ (band 2 of Landsat-8).

\begin{tabular}{|c|c|c|c|c|c|c|c|c|c|c|}
\hline \multirow{2}{*}{ Date } & \multirow{2}{*}{ DOY } & \multirow{2}{*}{ SZA (deg) } & \multirow{2}{*}{ SAA (deg) } & \multirow{2}{*}{ AOT } & \multirow{2}{*}{ Atm. Model } & \multicolumn{5}{|c|}{ Aerosol Type } \\
\hline & & & & & & $N$ & $r(\mu \mathrm{m})$ & $\log \sigma$ & $\operatorname{Re}$ & $I m$ \\
\hline 27 Oct. 2016 & 301 & 51.42 & 158.88 & 0.087 & Mid Lat. Summer & 1.0000 & 0.0206 & 0.3017 & 1.5848 & 0.0558 \\
\hline 31 Jan. 2017 & 31 & 58.14 & 152.51 & 0.079 & Mid Lat. Winter & 1.0000 & 0.0266 & 0.3242 & 1.6000 & 0.0373 \\
\hline 20 Mar. 2017 & 79 & 41.98 & 144.46 & 0.476 & Mid Lat. Winter & 1.0000 & 0.0268 & 0.3323 & 1.5926 & 0.0231 \\
\hline 23 May 2017 & 143 & 23.47 & 125.76 & 0.225 & Mid Lat. Summer & 1.0000 & 0.0246 & 0.3165 & 1.5867 & 0.0351 \\
\hline
\end{tabular}

(width), Re (real part of refractive index), and Im (imaginary part of refractive index), resulting from the Mie scattering calculation (Figure 4).

Figure 5(a) shows an example of total radiance simulated with MODTRAN. The geometry and atmospheric conditions are those on 31 January 2017, with the assumed surface reflectance of $\rho=0.30$. The normalized band response functions of the OLI sensor onboard Landsat-8 are illustrated in Figure 5(b). For the present image analysis, band-2 centered at $482 \mathrm{~nm}$ (with $\lambda_{1}=452 \mathrm{~nm}$ and $\lambda_{2}=$ $512 \mathrm{~nm}$ ) is utilized for the construction of the lookup table.

Figure 6 shows an example of the lookup table calculated for band- 2 of Landsat-8 satellite. For the simulation using MODTRAN, the aerosol type and geometrical conditions are assumed to be those around 10:00 JST on 31 January 2017. Figure 6(a) shows how the apparent reflectance, $\rho_{a p}$, changes as a function of the surface reflectance, $\rho$, for various values of AOT at $550 \mathrm{~nm}, \tau_{550}$. It is seen that the value of $\rho_{a p}$ increases with $\rho$. Some deviations are noticeable for small values of $\rho$ because of the influence of atmospheric scattering due to air molecules and aerosol particles. Nevertheless, since the relation between $\rho_{a p}$ and $\rho$ do not change significantly when $\tau_{550}$ is changed between 0 and 1 , it is understood that the value of surface reflectance can be estimated from the apparent reflectance. Figure 6(b), on the other hand, shows the relation between $\rho$ and $\tau_{550}$ for various values of $\rho_{a p}$. From this figure, it is seen that for a fixed value of $\tau_{a p}$, the dependence of $\rho$ on $\tau_{550}$ becomes noticeable for smaller values of $\rho_{a p}$ $(<0.15)$.

Figures 7(a)-(d) show the apparent reflectance $\left(\rho_{a p}\right)$ distribution over the Kanto area obtained by applying Equation (8) to the four Landsat- 8 band- 2 images when the concurrent observations were performed. Since the AOT value and aerosol properties are known from the ground-based observations, considerations explained in Figure 6 can readily be applied to estimate the distribution of the surface reflectance. In Figure 7(a) and Figure 7(b), the resulting values of the apparent reflectance, $\rho_{a p}$, are rather large, and particular enhancement is found in the urban area, e.g., around the coastal area of the Tokyo Bay. In Figure 7 (c) and Figure 7(d), on the other hand, the values of $\rho_{a p}$ are rather suppressed, indicating the influence of decreased transmittance due to relatively large values of AOT (Table 2). 


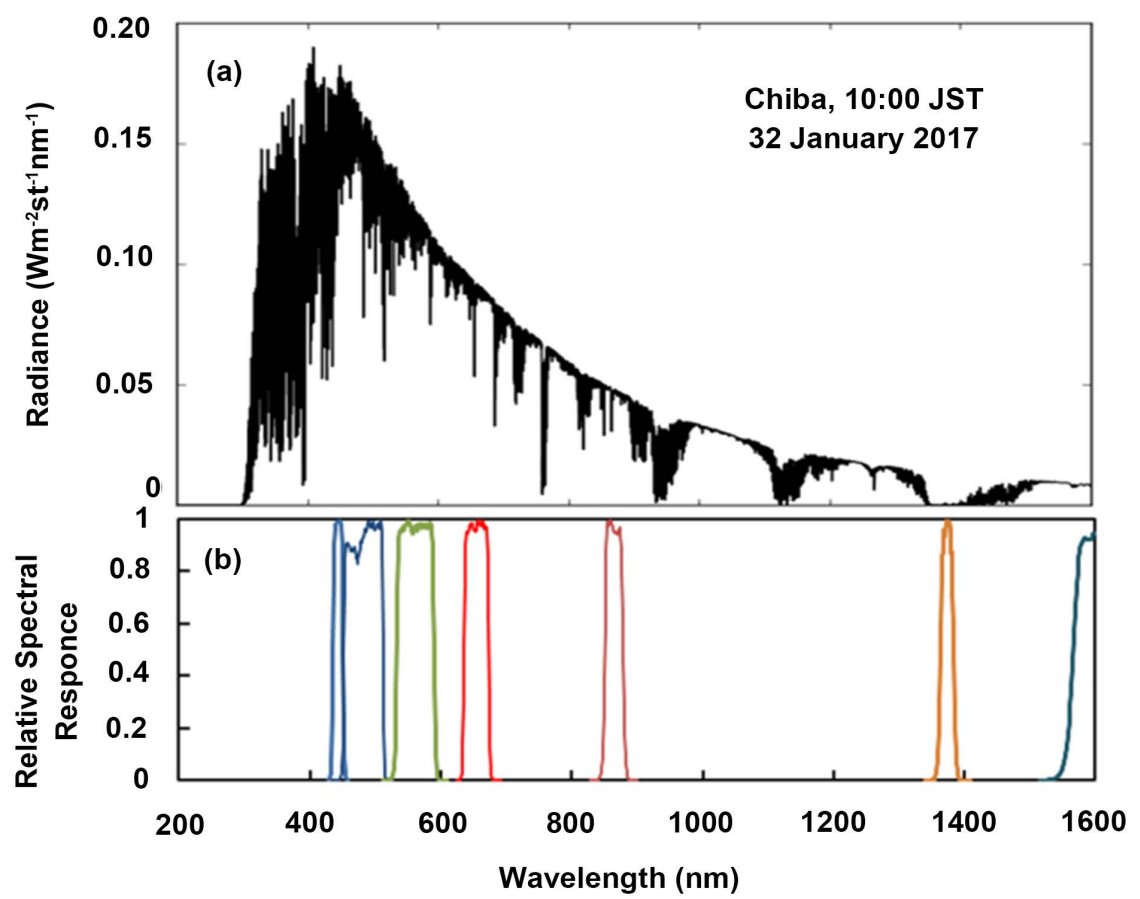

Figure 5. (a) At-sensor radiance at around 10:00 JST on 31 January 2017 simulated with the MODTRAN code assuming a surface reflectance of $\rho=0.30$; (b) Spectral response functions of Landsat- 8 OLI sensor in the wavelength range between 200 and $1600 \mathrm{~nm}$.

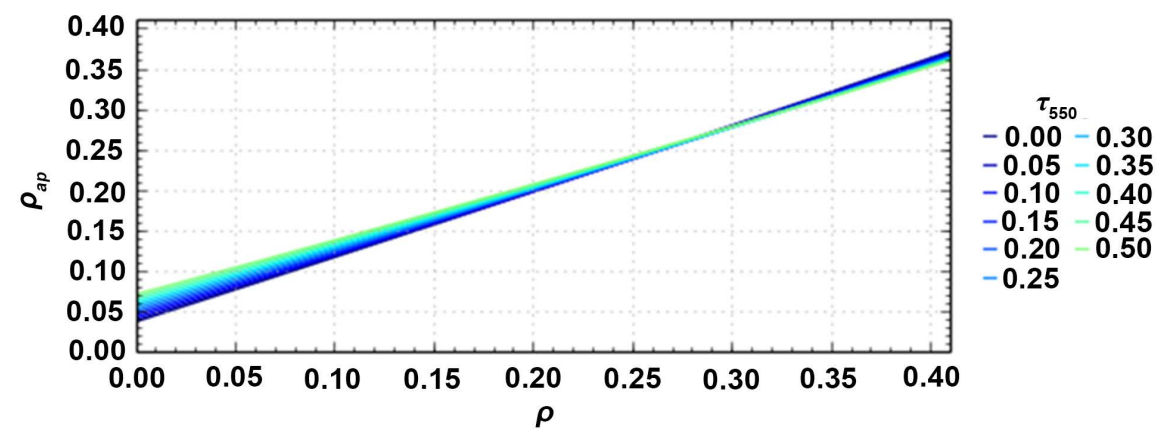

(a)

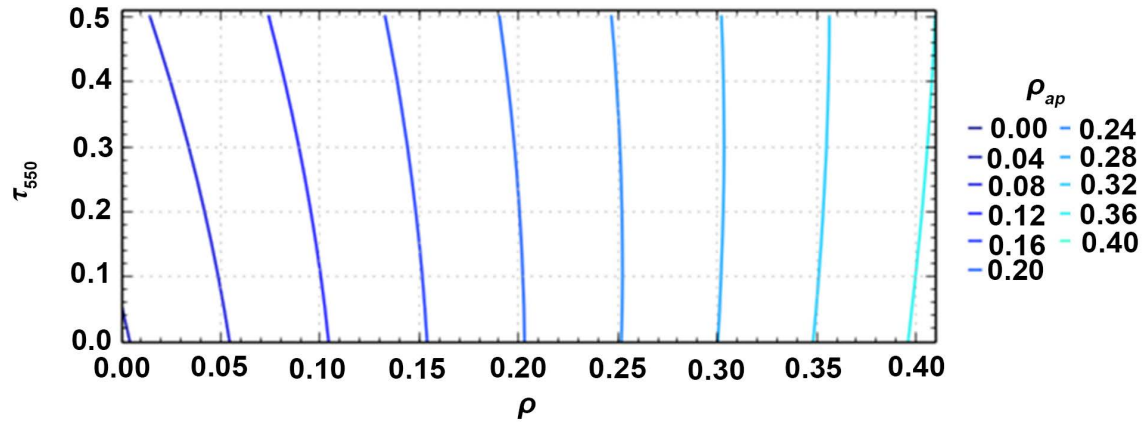

(b)

Figure 6. MODTRAN simulation of the apparent reflectance, $\rho_{a p}$, as a function of the surface reflectance, $\rho$, and AOT at $550 \mathrm{~nm}, \tau_{550}$, for the aerosol type and geometrical conditions around 10:00 JST on 31 January 2017. (a) The value of $\rho_{a p}$ increases with $\rho$ : the deviation is noticeable for small values because of the influence of atmospheric scattering; (b) The relation between $\rho$ and $\tau_{550}$ for various values of $\rho_{a p}$. 


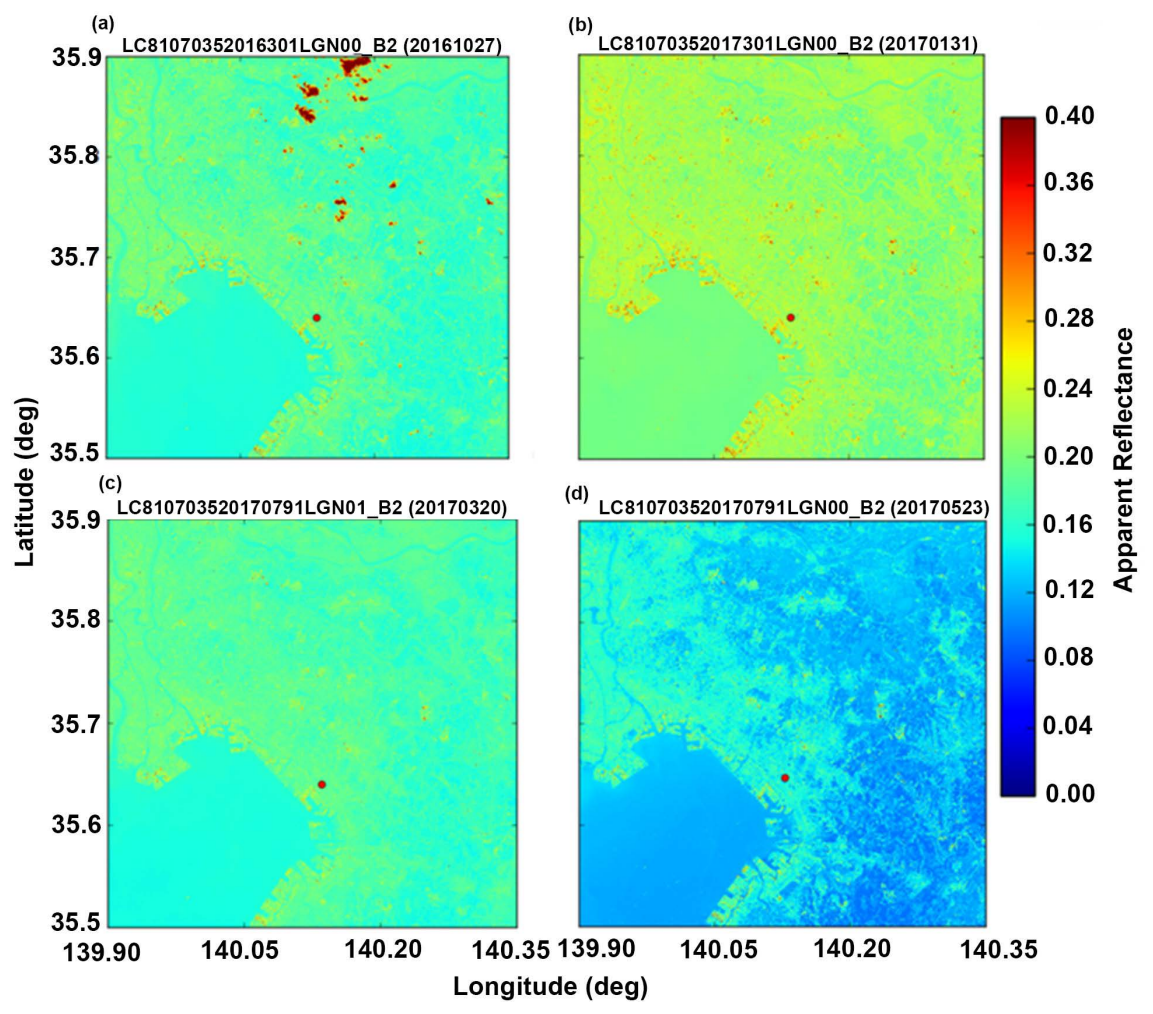

Figure 7. Distribution of the apparent reflectance of Landsat- 8 band-2 images for the four cases of concurrent observations: (a) 27 October 2016; (b) 31 January 2017; (c) 20 March 2017; and (d) 23 May 2017. In each panel, red dot shows the location of CEReS.

\subsection{Correlation between Space and Surface Observations}

Figure 8 shows the spatial distributions of AEC $\left(\alpha_{e x t}\right)$ derived by processing the PPI signal using Equation (5). In this calculation, the value of lidar ratio, $S_{1}$, listed in Table 1 has been utilized for each of the concurrent observations. The near-end boundary values of AEC at $349 \mathrm{~nm}$ are assumed to be given by the sampling result (AEC and Angstrom exponent) also shown in Table 1. From Figure 8, it is seen that the highest and lowest values of AEC are distributed on 20 March 2017 (Figure 8(c)) and 31 January 2017 (Figure 8(b)), respectively. The decreasing trend of AEC with radial distance is due to the slight $\left(\sim 4^{\circ}\right)$ elevation angle of the PPI observation. Other than this effect, the distributions are found to be more or less homogeneous.

Figure 9 shows the spatial distribution of AOT at $482 \mathrm{~nm}$ derived from band-2 of Landsat- 8 by employing the methodology explained in Section 2.4. Figure 9(a) shows the AOT distribution on 27 October 2016: nearly homogeneous values are obtained $\left(\tau_{482}=0.06-0.08\right)$, except in the north part of Kanto area. The smallest condition is seen on (b) 31 January 2017, with a homogeneous distribution of AOT $\left(\tau_{482}=0.05-0.07\right)$. The highest AOT $\left(\tau_{482}=0.45-0.50\right)$ is seen on (c) 20 March 2017. In Figure 9(d) (23 May 2017) inhomogeneity of AOT $\left(\tau_{482}=0.20-0.30\right)$ is found, which is more conspicuous than the other cases. It is noted that in Table 2, the highest AOT is seen on (c) 20 March 2017 
(a) 2016-10-27

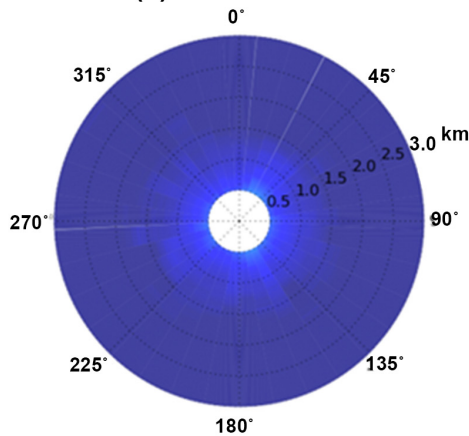

(c) $2017-03-20$

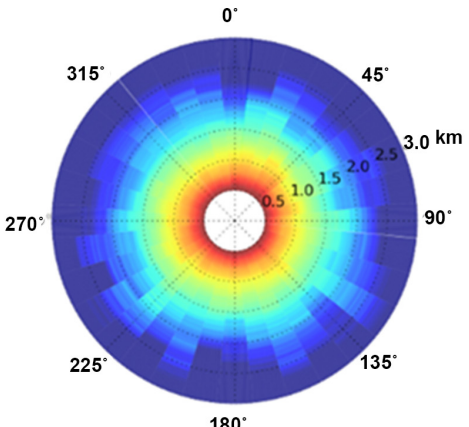

(b) 2017-01-31

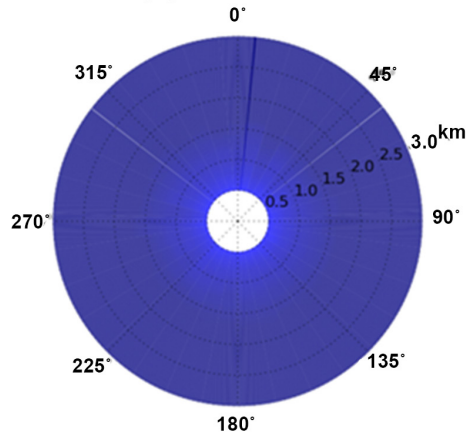

(d) 2017-05-23

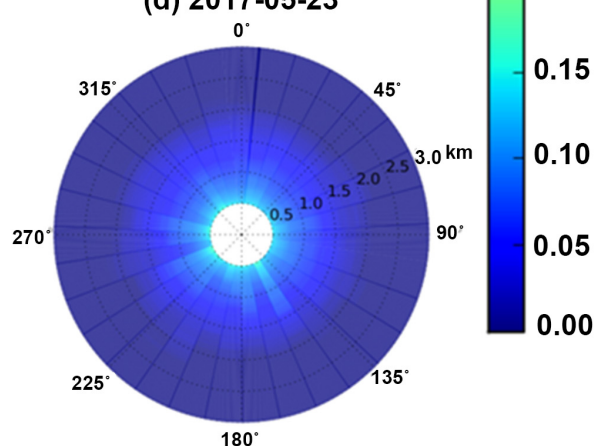

0.20

15

10

0.05

.00

Figure 8. Spatial distribution of AEC at $349 \mathrm{~nm}$ derived from the Fernald analysis of PPI lidar signals recorded at the time of Landsat- 8 satellite overpass.

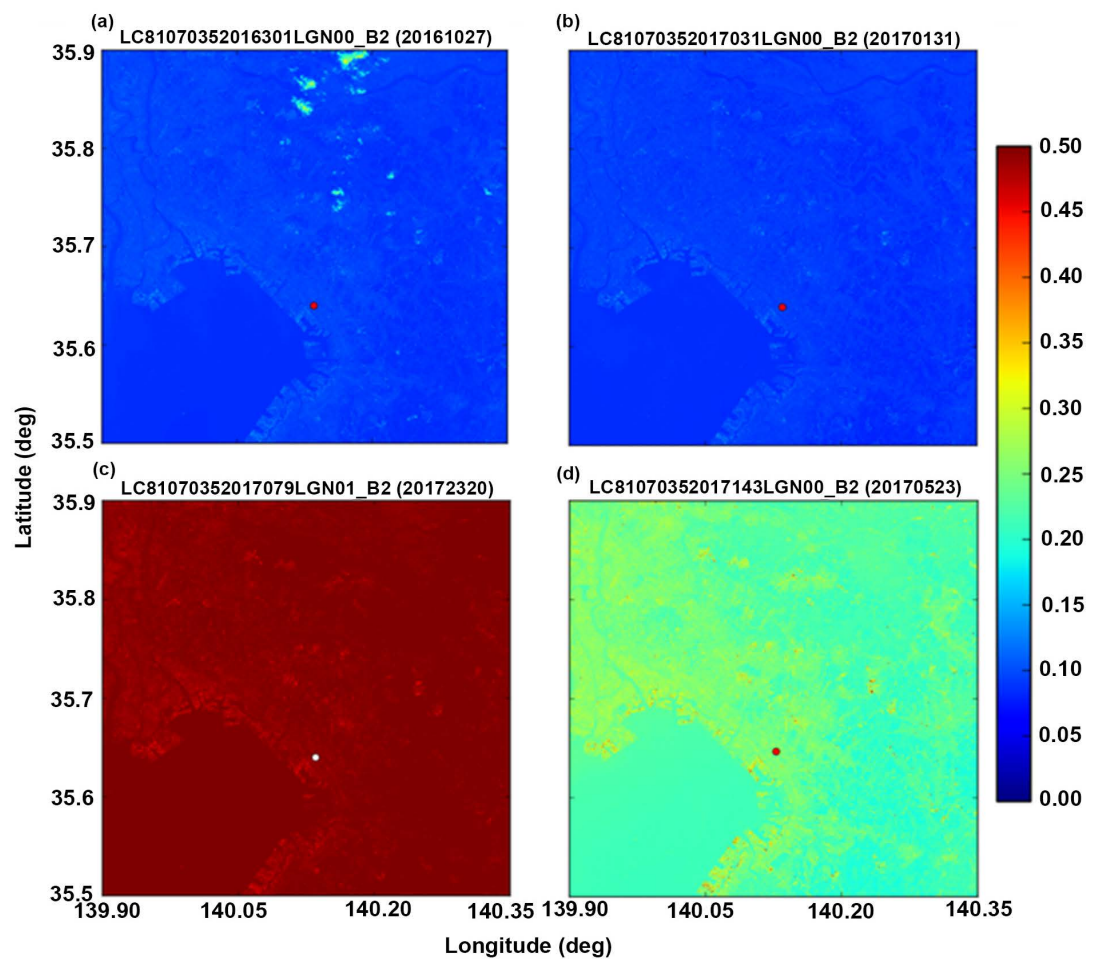

Figure 9. AOT at $482 \mathrm{~nm}$ derived from the analysis of band-2 images of Landsat- 8 OLI, at the time of satellite overpass around 10:00 JST on (a) 27 October 2016; (b) 31 January 2017; (c) 20 March 2017; and (d) 23 May 2017. The highest AOT distribution is seen in (c) $\left(\tau_{482}=0.45-0.50\right)$ while the smallest in (b) $\left(\tau_{482}=0.05-0.07\right)$. 
$\left(\tau_{482}=0.476\right)$ while the smallest on (b) 31 January $2017\left(\tau_{482}=0.079\right)$ : these values have been used to convert the apparent reflectance $\left(\rho_{a p}\right.$, Figure 7$)$ to the pixel reflectance $(\rho)$, which in turn has been exploited to determine the AOT distribution in Figure 9 from the condition of $L_{o b s}=L_{t o p}$ as explained in Section 2.4.

The main purpose of this novel monitoring technique is the comparison of AEC distribution derived from PPI lidar (Figure 8) and AOT distribution obtained from band- 2 of Landsat-8 satellite OLI sensor (Figure 9). The lowest AEC values among the four days are observed on 31 January 2017 (Figure 8(b)). This condition of small aerosol loading is consistent with the spatial distribution of AOT derived from the satellites observation shown in Figure 9(b), which exhibits the lowest AOT distribution as compared with other three days. In a similar way, it has been confirmed through the present results (Figure 8 and Figure 9) that the higher the AEC, the higher the AOT. This is a consequence of the fact that unless an additional layer of aerosol is existent in an elevated altitude, the vertical aerosol distribution, $a_{\text {ext }}(z)$, can usually be described as $a_{\text {ext }}(z)=a_{\text {ext }}(0)$ $\exp \left(-z / h_{a}\right)$, where $h_{a}$ is a parameter called the aerosol scale height $\left(h_{a} \sim 1-2 \mathrm{~km}\right)$, and $a_{e x t}(0)$ is the AEC directly measured with the PPI lidar. The value of AOT, on the other hand, can be obtained by integrating $a_{\text {ext }}(z)$ over the whole troposphere, leading to the expression of $\tau_{\mathrm{A}} \sim h_{a} a_{\text {ext }}(0)$. This indicates that AOT is nearly proportional to AEC, though the change in $h_{a}$ may cause some deviations. In the four cases reported in the present paper, the estimated value of $h_{a}$ is around $1 \mathrm{~km}$, though the value is slightly large $(-2 \mathrm{~km})$ for the case of (d) 23 May 2017.

\section{Conclusion}

A novel monitoring technique for retrieving the spatial distribution of atmospheric aerosol optical properties has been proposed and demonstrated. The PPI lidar provides the distribution of AEC in the atmospheric boundary layer with the help of data from ground-sampling instruments (an integrating nephelometer, an aethalometer, and optical particle counters) to determine the lidar ratio in addition to the near-end boundary values of AEC. For this purpose, the Mie scattering calculation has been conducted. Besides, this procedure provides the parameters that define the aerosol type as needed for the MODTRAN computation. In the MODTRAN simulation of the satellite-observed radiance, the AOT data from the sunphotometer is also exploited for determining the reflectance distribution from a satellite image, which, in turn, is used to derive the spatial distribution of AOT for the band-2 (blue band) of Landsat OLI. Through this analysis, good consistency has been found between the spatial distribution of AEC from the PPI lidar and that of AOT from the satellite sensor. As a whole, the present work has demonstrated that aerosol characterization based on ground-based observations is useful for obtaining detailed insight into the horizontal distribution of near-surface aerosol, which also yields better constraint on the atmospheric correction of satellite remote sensing data. Future extension of the present method 
may involve more frequent observation (i.e., rapid scan) of the PPI lidar measurement with preferably higher laser power (i.e., wide range coverage) so that the temporal as well as spatial variation of near-surface aerosol can be monitored on an operational basis.

\section{Acknowledgements}

The first author (JA) would like to thank to Ministry of Research, Technology, and Higher Education Republic of Indonesia for supporting fellowship named Beasiswa Dikti.

\section{Conflicts of Interest}

The authors declare no conflicts of interest regarding the publication of this paper.

\section{References}

[1] IPPC (2007) Climate Change 2007: The Physical Science Basis. IPPC, Geneva, Switzerland.

[2] Seinfeld, H. and Pandis, S. (1998) Atmospheric Chemistry and Physics, from Air Pollution to Climate Change. John Wiley \& Sons, New York, USA.

[3] Jaenicke, R. (1993) Tropospheric Aerosols in Aerosol-Cloud-Climate Interaction. Academic Press, Cambridge.

[4] Kuze, H. (2012) Multi-Wavelength and Multi-Direction Remote Sensing of Atmospheric Aerosols and Clouds, Remote Sensing-Applications. InTech Publication, 279-294.

https://www.intechopen.com/books/remote-sensing-applications/multi-wavelength -and-multi-direction-remote-sensing-of-atmospheric-aerosols-and-clouds

[5] Chung, C.E. (2012) Aerosol Direct Radiative Forcing: A Review. InTech Publication, 379-394.

https://www.intechopen.com/books/atmospheric-aerosols-regional-characteristicsc hemistry-and-physics/aerosol-direct-radiative-forcing-a-review

[6] Tiwari, S. and Singh, A.K. (2013) Variability of Aerosol Parameters Derived from Ground and Satellite Measurements over Varanasi Located in the Indo-Gangetic Basin. Aerosol and Air Quality Research, 13, 627-638.

https://doi.org/10.4209/aaqr.2012.06.0162

[7] Sun, L., Wei, J., Bilal, M., Tian, X., Jia, C., Guo, Y. and Mi, X. (2016) Aerosol Optical Depth Retrieval over Bright Areas Using Landsat 8 OLI Images. Remote Sensing, 8 , 1-14. https://doi.org/10.3390/rs8010023

[8] Uesawa, D. (2016) Aerosol Optical Depth Product Derived from Himawari-8 Data for Asian Dust Monitoring. Meteorological Satellite Center Technical Note, No. 61, 59-63. https://www.data.jma.go.jp/mscweb/technotes/msctechrep61-6.pdf

[9] Manago, N., Miyazawa, S., Bannu and Kuze, H. (2011) Seasonal Variation of Tropospheric Aerosol Properties by Direct and Scattered Solar Radiation Spectroscopy. Journal of Quantitative Spectroscopy and Radiative Transfer, 112, 285-291. https://doi.org/10.1016/j.jqsrt.2010.06.015

[10] Di Girolamo, P., Summa, D., Bhawar, R., Di Iorio, T., Cacciani, M., Veselovskii, I., Dubovik, O. and Kolgotin, A. (2012) Raman Lidar Observations of a Saharan Dust 
Outbreak Event: Characterization of the Dust Optical Properties and Determination of Particle Size and Microphysical Parameters. Atmospheric Environment, 50, 66-78. https://doi.org/10.1016/j.atmosenv.2011.12.061

[11] Sakai, T., Nagai, T., Mano, Y., Zaizen, Y. and Inomata, Y. (2012) Aerosol Optical and Microphysical Properties as Derived from Collocated Measurements Using Polarization Lidar and Direct Sampling. Atmospheric Environment, 60, 419-427. https://doi.org/10.1016/j.atmosenv.2012.06.068

[12] Queface, A.J., Piketh, S.J., Eck, T.F., Tsay, S.-C. and Mavume, A.F. (2011) Climatology of Aerosol Optical Properties in Southern Africa. Atmospheric Environment, 45, 2910-2921. https://doi.org/10.1016/j.atmosenv.2011.01.056

[13] Kinjo, H., Kuze, H., Takamura, T., Yabuki, M. and Takeuchi, N. (2001) Determination of Aerosol Extinction-to-Backscattering Ratio from Multiwavelength Lidar Observation. Japanese Journal of Applied Physics, 40, 434-440.

https://doi.org/10.1143/JJAP.40.434

[14] Mabuchi, Y., Manago, N., Bagtasa, G., Saitoh, H., Takeuchi, N., Yabuki, M., Shiina, T. and Kuze, H. (2012) Multi-Wavelength Lidar System for the Characterization of Tropospheric Aerosols and Clouds. 2012 IEEE International Geoscience and Remote Sensing Symposium, Munich, 22-27 July 2012, 2505-2508. https://doi.org/10.1109/IGARSS.2012.6351839

[15] Yabuki, M., Kuze, H., Kinjo, H. and Takeuchi, N. (2003) Determination of Vertical Distributions of Aerosol Optical Parameters by Use of Multi-Wavelength Lidar Data. Japanese Journal of Applied Physics, 42, 686-694. https://doi.org/10.1143/JJAP.42.686

[16] Lagrosas, N., Yoshii, Y., Kuze, H., Takeuchi, N., Naito, S., Sone, A. and Kan, H. (2004) Observation of Boundary Layer Aerosols Using a Continuously Operated, Portable Lidar System. Atmospheric Environment, 38, 3885-3892. https://doi.org/10.1016/j.atmosenv.2004.02.060

[17] Kuze, H. (2012) Characterization of Tropospheric Aerosols by Ground-Based Optical Measurements. SPIE Newsroom, 2-4.

http://spie.org/newsroom/4555-characterization-of-tropospheric-aerosols-by-groun d-based-optical-measurements?ArticleID $=x 91184 \& S S O=1$

[18] Kuze, H., Lagrosas, N., Aminuddin, J. and Manago, N. (2016) Study on the Relation of Aerosol Sampling Data and Aerosol Optical Characteristic. ISRS 2016, Jeju, Korea.

[19] Cachorro, V., De Frutos, A. and Gonzalez, M. (1993) Analysis of the Relationships between Junge Size Distribution and Ångström $\alpha$ Turbidity Parameters from Spectral Measurements of Atmospheric Aerosol Extinction. Atmospheric Environment Part A General Topics, 27, 1585-1591. https://doi.org/10.1016/0960-1686(93)90158-U

[20] Jung, C.H., Um, J., Lee, J.Y. and Kim, Y.P. (2013) Sensitivity Analysis of the Angstrom Exponent for Multimodal Aerosol Size Distributions. Asia-Pacific Journal of Atmospheric Sciences, 49, 625-634. https://doi.org/10.1007/s13143-013-0055-5

[21] Aminuddin, J., Suenaga, Y., Tsuneyoshi, T., Okude, S., Lagrosas, N., Manago, N. and Kuze, H. (2016) Plan Position Indicator (PPI) Lidar Measurement of Horizontal Distribution of Aerosol Extinction Coefficient. 34th Japanese Laser Sensing Symposium, Hiroshima, 31 October-2 November 2017, 148-149. https://laser-sensing.jp/34thLSS/34th_papers/0147_P-C19_aminuddin.pdf

[22] Fernald, F.G. (1984) Analysis of Atmospheric Lidar Observations: Some Comments. 
Applied Optics, 23, 652. https://doi.org/10.1364/AO.23.000652

[23] Qiu, J. (1998) A Method to Determine Atmospheric Aerosol Optical Depth Using Total Direct Solar Radiation. Journal of the Atmospheric Sciences, 55, 744-757. https://doi.org/10.1175/1520-0469(1998)055<0744:AMTDAA >2.0.CO;2

[24] Cerqueira, J.G., Fernandez, J.H., Hoelzemann, J.J., Leme, N.M.P. and Sousa, C.T. (2014) Langley Method Applied in Study of Aerosol Optical Depth in the Brazilian Semiarid Region Using 500, 670 and $870 \mathrm{~nm}$ Bands for Sun Photometer Calibration. Advances in Space Research, 54, 1530-1543. https://doi.org/10.1016/j.asr.2014.06.006

[25] Zieger, P., Fierz-Schmidhauser, R., Weingartner, E. and Baltensperger, U. (2013) Effects of Relative Humidity on Aerosol Light Scattering: Results from Different European Sites. Atmospheric Chemistry and Physics, 13, 10609-10631. https://doi.org/10.5194/acp-13-10609-2013

[26] Bodhaine, B.A., Wood, N.B., Dutton, E.G. and Slusser, J.R. (1999) On Rayleigh Optical Depth Calculations. Journal of Atmospheric and Oceanic Technology, 16, 1854-1861. https://doi.org/10.1175/1520-0426(1999)016<1854:ORODC >2.0.CO;2

[27] Soni, K., Singh, S., Bano, T., Tanwar, R.S. and Nath, S. (2011) Wavelength Dependence of the Aerosol Angstrom Exponent and Its Implications over Delhi, India. Aerosol Science and Technology, 45, 1488-1498. https://doi.org/10.1080/02786826.2011.601774

[28] Tijjani, B.I. and Uba, S. (2012) Dependence of the Angstrom Exponents on Wavelength and Relative Humidities for Four Types of Aerosols. International Journal of Research and Revies in Applied Sciences, 2, 1085-1102.

[29] Kaufman, Y.J., Fraser, R.S. and Mahoney, R.L. (1991) Fossil Fuel and Biomass Burning Effect on Climate-Heating or Cooling? Journal of Climate, 4, 578-588.

[30] Eck, T.F., Holben, B.N., Reid, J.S., Dubovik, O., Smirnov, A., O’Neill, N.T., Slutsker, I. and Kinne, S. (1999) Wavelength Dependence of the Optical Depth of Biomass Burning, Urban, and Desert Dust Aerosols. Journal of Geophysical Research, 104, 31333-31350. https://doi.org/10.1029/1999JD900923

[31] Dubovik, O., Holben, B., Eck, T.F., Smirnov, A., Kaufman, Y.J., King, M.D., Tanré, D. and Slutsker, I. (2002) Variability of Absorption and Optical Properties of Key Aerosol Types Observed in Worldwide Locations. Journal of the Atmospheric Sciences, 59, 590-608. https://doi.org/10.1175/1520-0469(2002)059<0590:VOAAOP >2.0.CO;2

[32] Marino, E., Ranz, P., Tome, J.L., Noriega, M.A., Esteban, J., Madrigal, J., Luis, J., Ángel, M., Esteban, J. and Madrigal, J. (2016) Generation of High-Resolution Fuel Model Maps from Discrete Airborne Laser Scanner and Landsat-8 OLI: A Low-Cost and Highly Updated Methodology for Large Areas. Remote Sensing of Environment, 187, 267-280. https://doi.org/10.1016/j.rse.2016.10.020

[33] Schroeder, W., Olivia, P., Giglio, L., Quayle, B., Lorenz, E. and Morelli, F. (2016) Active Fire Detection Using Landsat-8/OLI Data. Remote Sensing of Environment, 185, 210-220. https://doi.org/10.1016/j.rse.2015.08.032

[34] Bannari, A., El-Battay, A., Hameid, N. and Tashtoush, F. (2017) Salt-Affected Soil Mapping in an Arid Environment Using Semi-Empirical Model and Landsat-OLI Data. Advances in Remote Sensing, 6, 260-291. https://doi.org/10.4236/ars.2017.64019

[35] Rees, W.G. (2010) Physical Principles of Remote Sensing. 3rd Edition, Cambridge University Press, Cambridge.

[36] Chandrasekhar, S. (1960) Radiative Transfer. Dover Publications, Inc., New York. 
[37] Kneizys, F.X., Anderson, G.P., Shettle, E.P., Gallery, W.O., Abreu, L.W., Selby, J.E.A., Chetwynd, J.H. and Clough, S.A. (1988) Users Guide to LOWTRAN 7. AFGL-TR-88-0177 Environmental Research Papers No. 1010.

[38] Berk, A., Anderson, G.P., Acharya, P.K., Chetwynd, J.H., Bernstein, L.S., Shettle, E.P., Matthew, M.W., Sciences, S., Force, A., Directorate, S.V., Command, M. and Division, R.S. (1999) Modtran4 User's Manual.

[39] Vermote, E., Herman, M., Morcrette, J.J. and Kotchenova, S.Y. (2006) Second Simulation of a Satellite Signal in the Solar Spectrum-Vector (6SV).

[40] Vermote, E.F. and Deuzc, J.L. (1997) Second Simulation of the Satellite Signal in the Solar Spectrum, 6s: An Overview. IEEE Transactions on Geoscience and Remote Sensing, 35, 675-686. https://doi.org/10.1109/36.581987

[41] Kaufman, Y.J., Tanré, D., Remer, L.A., Vermote, E.F., Chu, A. and Holben, B.N. (1997) Operational Remote Sensing of Tropospheric Aerosol over Land from EOS Moderate Resolution Imaging Spectroradiometer. Journal of Geophysical Research, 102, 17051-17067. https://doi.org/10.1029/96JD03988

[42] Acharya, P.K., Berk, A., Anderson, G.P., Larsen, N.F., Tsay, S.-C. and Stamnes, K.H. (1999) MODTRAN4: Multiple Scattering and Bi-Directional Reflectance Distribution Function (BRDF) Upgrades to MODTRAN. Proceedings of SPIE, 3756, 354-362. https://doi.org/10.1117/12.366389

[43] Minomoura, M., Kuze, H. and Takeuchi, N. (2001) Atmospheric Correction of Visible and Near-Infrared Satellite Data Using Radiance Components: An Improved Treatment of Adjacency Effect. Journal of the Remote Sensing Society of Japan, 21, 260-271. https://www.jstage.jst.go.jp/article/rssj1981/21/3/21_3_260/_pdf

[44] Kotchenova, S.Y. and Vermote, E.F. (2007) Validation of a Vector Version of the 6S Radiative Transfer Code for Atmospheric Correction of Satellite Data. Part II. Homogeneous Lambertian and Anisotropic Surfaces. Applied Optics, 46, 4455-4464. https://doi.org/10.1364/AO.46.004455

[45] Kotchenova, S.Y., Vermote, E.F., Levy, R. and Lyapustin, A. (2008) Radiative Transfer Codes for Atmospheric Correction and Aerosol Retrieval: Intercomparison Study. Applied Optics, 47, 2215-2226. https://doi.org/10.1364/AO.47.002215

[46] Minomura, M., Kuze, H. and Takeuchi, N. (2001) Adjacency Effect in the Atmospheric Correction of Satellite Remote Sensing Data: Evaluation of the Influence of Aerosol Extinction Profiles. Optical Review, 8, 133-141. https://doi.org/10.1007/s10043-001-0133-2

[47] Aminuddin, J., Okude, S., Lagrosas, N., Manago, N. and Kuze, H. (2018) Real Time Derivation of Atmospheric Aerosol Optical Properties by Concurrent Measurements of Optical and Sampling Instruments. Open Journal of Air Pollution, 7, 140-155. https://doi.org/10.4236/ojap.2018.72008 


\section{List of Abbreviations}

6S : Second Simulation of a Satellite Signal in the Solar Spectrum

AEC : Aerosol Extinction Coefficient

AOT : Aerosol Optical Thickness

AU : Astronomical Unit

CEReS : Center for Environmental Remote Sensing

DN : Digital Number

JST : Japan Standard Time

LOWTRAN : LOW Resolution Atmospheric Radiance and TRANsmittance

MODIS : MODerate Resolution Imaging Spectroradiometer

MODTRAN : MODerate Resolution Atmospheric TRANSmittance

OLI : Operational Land Imager

OPC : Optical Particle Counter

PMT : Photo Multiplier Tube

PPI : Plan Position Indicator

SP : Slant Path 